\title{
Meridional transport of salt in the global ocean from an eddy-resolving model
}

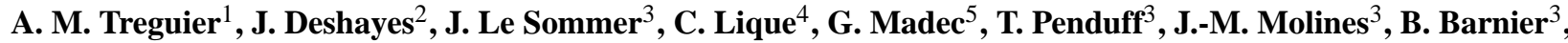 \\ R. Bourdalle-Badie ${ }^{6}$, and C. Talandier ${ }^{1}$ \\ ${ }^{1}$ Laboratoire de Physique de Oceans, CNRS-IFREMER-IRD-UBO, Plouzané, France \\ ${ }^{2}$ LPO, Brest, IRD and University of Cape Town, Cape Town, South Africa \\ ${ }^{3}$ LGGE, UMR5183, CNRS-UJF, Grenoble, France \\ ${ }^{4}$ Department of Earth Sciences, University of Oxford, Oxford, UK \\ ${ }^{5}$ LOCEAN-IPSL, CNRS-IRD-UPMC-MNHN, Paris, France \\ ${ }^{6}$ Mercator-Ocean, Toulouse, France
}

Correspondence to: A. M. Treguier (treguier@ifremer.fr)

Received: 14 November 2013 - Published in Ocean Sci. Discuss.: 5 December 2013

Revised: 11 February 2014 - Accepted: 27 February 2014 - Published: 17 April 2014

\begin{abstract}
The meridional transport of salt is computed in a global eddy-resolving numerical model $\left(1 / 12^{\circ}\right.$ resolution) in order to improve our understanding of the ocean salinity budget. A methodology is proposed that allows a global analysis of the salinity balance in relation to surface water fluxes, without defining a "freshwater anomaly" based on an arbitrary reference salinity. The method consists of a decomposition of the meridional transport into (i) the transport by the time-longitude-depth mean velocity, (ii) time-mean velocity recirculations and (iii) transient eddy perturbations. Water is added (rainfall and rivers) or removed (evaporation) at the ocean surface at different latitudes, which creates convergences and divergences of mass transport with maximum and minimum values close to $\pm 1 \mathrm{~Sv}$. The resulting meridional velocity effects a net transport of salt at each latitude ( \pm 30 Sv PSU), which is balanced by the time-mean recirculations and by the net effect of eddy salinity-velocity correlations. This balance ensures that the total meridional transport of salt is close to zero, a necessary condition for maintaining a quasi-stationary salinity distribution. Our model confirms that the eddy salt transport cannot be neglected: it is comparable to the transport by the time-mean recirculation (up to $15 \mathrm{~Sv}$ PSU) at the poleward and equatorial boundaries of the subtropical gyres. Two different mechanisms are found: eddy contributions are localized in intense currents such as the Kuroshio at the poleward boundary of the subtropical gyres, while they are distributed across the basins at
\end{abstract}

the equatorward boundaries. Closer to the Equator, salinityvelocity correlations are mainly due to the seasonal cycle and large-scale perturbations such as tropical instability waves.

\section{Introduction}

The distribution of salinity in the global ocean is controlled by ocean-atmosphere exchanges as well as by the ocean circulation. The global distribution of surface salinity shows a clear relation with evaporation minus precipitation minus coastal runoff patterns (e.g. the atmospheric forcing, $E-P-R$ ), as shown in Fig. 1. Upper ocean salinity is high in the subtropical gyres, where evaporation dominates. It is lower in the subpolar regions and under the intertropical convergence zones, where precipitations dominate. The correlation between sea surface salinity and $E-P-R$ patterns has stimulated recent efforts in monitoring the surface salinity as an indicator of changes in the global hydrological cycle (Yu, 2011; Durack et al., 2012). Indeed, our knowledge of the water flux over the ocean is highly uncertain, due to the high intermittency and small spatial scales of precipitations. The ocean salinity, as an integrator of $E-P-R$ patterns, could give us indications of changes in the hydrological cycle over the ocean potentially more reliable than direct observations. This is the concept of "using the ocean as a rain gauge for the 


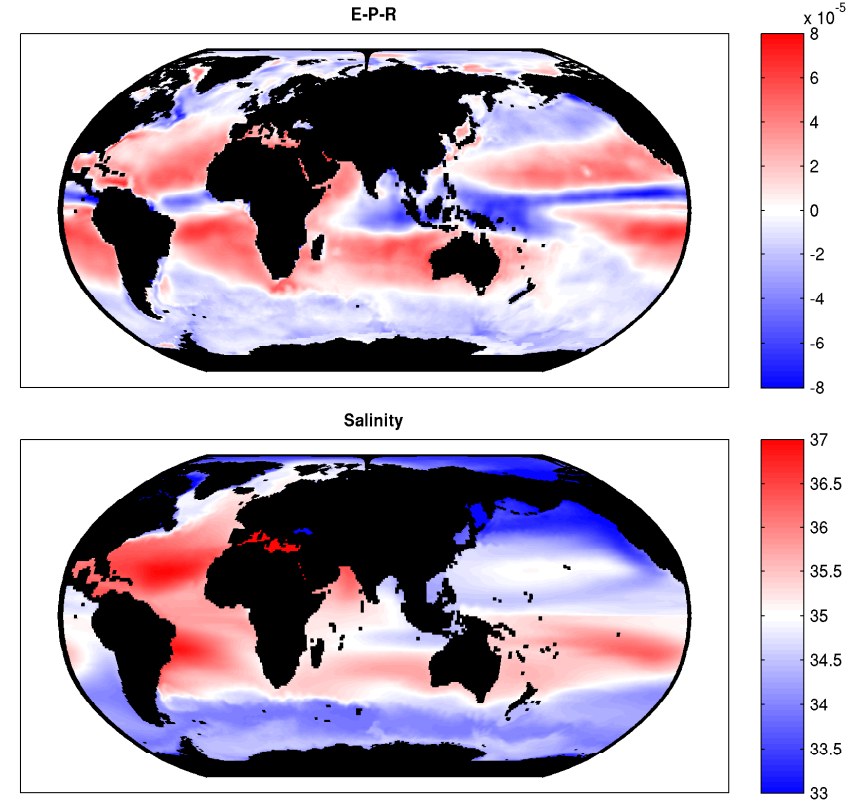

Fig. 1. Top panel: evaporation-precipitation-runoff flux for the global ORCA12 model $\left(\mathrm{kg} \mathrm{m}^{-2} \mathrm{~s}^{-1}\right)$. Positive values correspond to regions where evaporation is dominant. Bottom panel: salinity (PSU) averaged over the top $200 \mathrm{~m}$ in the ORCA12 model. It is a time-mean over the last 10 years of an 85 year-long experiment.

global water cycle", applied recently to the tropical oceans by Terray et al. (2012).

Applying this concept is far from trivial, because changes in salinity can reflect either changes in evaporation, precipitation, runoffs or changes in the ocean circulation. Ocean currents, from the large-scale gyres to mesoscale eddies, transport water masses with distinctive salinities far away from their region of origin. The relationship between the variability of ocean currents, $E-P-R$ and surface salinity has been evaluated at seasonal timescales by Yu (2011) from observations. She found that the seasonal cycle of mixed layer salinity is driven by different processes in different regions of the ocean: $E-P-R$ is the dominant process in the intertropical convergence zones, while advection by Ekman or geostrophic velocity plays a larger role in subtropical gyres. However, because of the scarcity of observations, the analysis of Yu (2011) relies on simplified equations, neglecting the nonlinear eddy contributions. Similarly, studies of the global transports of salt from in situ observations such as Talley (2008) or Ganachaud and Wunsch (2003) cannot shed light on the nonlinear mechanisms contributing to these transports.

In this paper we consider the transport of salt by the ocean circulation averaged over long timescales (decadal or longer). It is the integral of the product of velocity and salinity. Therefore, the time-averaged transport contains an "eddy" term arising from the correlation between fluctuations of velocity and salinity. Denoting by $b$ a section (or an ensemble of sections) bounding a closed region of the ocean,
$S$ the salinity, $v$ the velocity perpendicular to the boundary, the time average by an overbar and the departures from the time average by primes,

$$
\iint_{b} \overline{v S}=\iint_{b} \bar{v} \bar{S}+\iint_{b} \overline{v^{\prime} S^{\prime}} .
$$

One expects the effect of velocity-salinity correlations on the time-mean salt transport, $\overline{v^{\prime} S^{\prime}}$, to be significant especially in eddy-rich regions of the world ocean such as western boundaries or the Antarctic Circumpolar current. Stammer (1998) provided the first global estimate of eddy fluxes of salt based on a diffusive hypothesis. He computed a diffusion coefficient due to mesoscale eddies using satellite altimetry and combined it with large-scale salinity gradients from climatology. He found that the eddy salt transport was likely to be important in the same regions as the eddy heat transport (for example, the Antarctic Circumpolar current, the Gulf Stream and Kuroshio). However, his estimate was indirect and relied on hypotheses difficult to justify. For example, he computed the depth-integrated eddy salt transport as the product of a diffusivity at the ocean surface (derived from satellite observations) by a gradient of salinity averaged over the top $1000 \mathrm{~m}$ of the ocean. This method is questionable, because the eddy diffusivity in the ocean is not constant over the top $1000 \mathrm{~m}$ and there is no evidence suggesting that eddy fluxes vanish below $1000 \mathrm{~m}$.

High-resolution numerical ocean models are the only tools that allow us to estimate both time-mean and eddy contributions to Eq. (1) in a consistent manner. At the global scale, these models have become increasingly realistic in the past 20 years or so, and numerous studies have been devoted to eddy heat fluxes. Surprisingly, only a few so far have considered eddy salt fluxes. The role of eddies in the meridional transport of salt at the global scale has been explored by McCann et al. (1994), who were the first to estimate eddy salt transports in a quasi-global ocean model (excluding the Arctic Ocean). Their model had a $0.5^{\circ}$ grid. With such a low resolution, only the largest patterns of variability such as Agulhas rings or tropical instability waves could be simulated, so this first global estimate clearly needs revisiting. In this paper, we use a high-resolution global model to compute the eddy salt flux $\overline{v^{\prime} S^{\prime}}$, defined as the correlation of salinity and velocity fluctuations, and we argue that it plays a significant role in the time-averaged salinity balance of the global ocean.

Our study follows the regional model analysis of Treguier et al. (2012), focussed on the North Atlantic. We take advantage of a new global simulation at $1 / 12^{\circ}$ to extend our investigation to all ocean basins. We also build on the regional model analysis of Meijers et al. (2007), focussed on the Southern Ocean. Instead of salt transport, Meijers et al. (2007) considered "freshwater transport", where "freshwater" was defined as a salinity anomaly relative to a reference salinity (35 PSU). In the present paper, as in Treguier et al. (2012), we use salt transport rather than "freshwater" in order 
to avoid the use of an arbitrary reference salinity. We go further than Treguier et al. (2012) by proposing a decomposition of the salt transport into three components in the manner of Bryden and Imawaki (2001), rather than just the time-mean and eddy components defined in Eq. (1). This allows us to link the salt transport with the atmospheric forcing, just as if we were using the notion of "freshwater".

The global simulation used in this study is unique by the combination of its high spatial resolution (a quasi-isotropic grid of $1 / 12^{\circ}$ resolution at the Equator) and its length ( 85 years of simulation, forced by a repeated seasonal cycle); it is presented in Sect. 2. The rationale for the decomposition of salt transport into three components is presented in Sect. 3 and applied to the global model in Sect. 4. Spatial and temporal scales of eddy fluxes are analysed further in Sect. 5 . Conclusions and perspectives are presented in Sect. 6.

\section{Description of the global simulation}

ORCA12 is, so far, the highest resolution global model of the DRAKKAR hierarchy (Drakkar Group, 2007; Penduff et al., 2010) using the global ORCA tripolar grid (see for example Barnier et al., 2006, for a description of the $1 / 4^{\circ}$ version). The model is based on the NEMO platform (Madec, 2008, Nucleus for European Modelling of the Ocean) which includes the LIM ice model (Timmermann et al., 2005). Model resolutions of $1 / 10^{\circ}$ or more have been shown to drastically improve the representation of western boundary currents such as the Gulf Stream or the Kuroshio (Maltrud and McClean, 2005), and ORCA12 is no exception. The good performance of the $1 / 12^{\circ}$ grid for the representation of the Gulf Stream eddy dynamics is documented by Maze et al. (2013). ORCA12 is introduced in Hurlburt et al. (2009) and has been the global operational forecast model at Mercator-Ocean since 2011. The DRAKKAR group has used ORCA12 to perform ocean-ice simulations forced by the atmosphere over periods of 10 to 30 years. These simulations have been used, for example, to document the transport of salinity anomalies at $30^{\circ} \mathrm{S}$ in the Atlantic and its link with the stability of the Atlantic meridional overturning circulation (Deshayes et al., 2013).

For our purpose, which is to evaluate the eddy contribution to the time-mean transport of salt, it is important that the model salinity should not be drifting too rapidly from the observed climatology, because the meridional transport of salt is related to the change in salt content (e.g. Treguier et al., 2012). Models without data assimilation drift inevitably, due to errors in the numerics, parameterizations, and/or forcings. When the state of the atmosphere is fixed (in the statistical sense), the drift in the ocean usually becomes small at the end of long integrations (with durations of centuries to millenia). While such long simulations are routinely performed to equilibrate coupled climate models, they are not yet possible with costly high-resolution models such as ORCA12.
The longest simulation available (ORCA12-GJM02) is 85 years long. It has been forced by a repeated seasonal cycle of atmospheric forcing, the objective being a study of the intrinsic variability generated by the ocean at interannual timescales, following Penduff et al. (2011). The simulation has been run as a "Grand Challenge" at the IDRIS computing centre in Orsay (France), and its duration was dictated by the computing power available. The ORCA12 grid has $4322 \times 3059$ points horizontally and 46 vertical levels. The global domain was split into 3584 sub-domains on an IBM x3750 computer. The simulation required about 5 million hours of CPU time and generated 53 Tera-octets of output files. Only monthly averages were stored during the first 75 years of the experiment. During the last ten years, 5-day averages of surface fluxes and 3-D fields of temperature and velocity were archived, allowing us to evaluate the effects of transients (at timescales longer than 5 days). In this paper, time averages will be made over these final ten years of the experiment.

The grid size of ORCA12 is $9.25 \mathrm{~km}$ at the Equator, $4 \mathrm{~km}$ on average in the Arctic, and up to $1.8 \mathrm{~km}$ in the Ross and Weddell seas. In our simulations, the bathymetry is represented by partial steps (Barnier et al., 2006) and a linearized free surface formulation is used (Roullet and Madec, 2000). Free-slip boundary conditions are applied over most of the domain. The lateral mixing of tracers is parameterized by an isopycnal Laplacian operator with coefficient $100 \mathrm{~m}^{2} \mathrm{~s}^{-1}$ at the Equator, decreasing proportionally to the grid size. For the lateral mixing of momentum, a horizontal biharmonic operator is used with coefficient $1.25 \times 10^{10} \mathrm{~m}^{4} \mathrm{~s}^{-1}$ at the Equator, decreasing proportionally to the cube of the grid size. Vertical mixing of tracers and momentum is performed by a turbulent kinetic energy closure. Vertical mixing of tracers is enhanced $\left(10 \mathrm{~m}^{2} \mathrm{~s}^{-1}\right)$ in case of static instability. A diffusive and advective bottom boundary layer parameterization is added in order to improve the representation of dense overflows.

The atmospheric forcing is based on observed (satellite) and reanalysed atmospheric variables, following the method of Large and Yeager (2009) but taking variables from ECMWF instead of NCEP (Brodeau et al., 2010). The turbulent fluxes are calculated using the CORE bulk formulae of Large and Yeager (2004) excepted for the wind stress, which is calculated from the wind velocity only without taking into account the ocean currents. The construction of the seasonal cycle forcing is described in detail by Penduff et al. (2011). Coastal runoffs are prescribed using the climatology of Dai and Trenberth (2002). Coastal runoff from Antarctica $(0.083 \mathrm{~Sv})$ is distributed along the coast but also offshore to mimic the effect of iceberg drift, following Silva et al. (2006).

A restoring to the climatological salinity of Levitus is added, with a coefficient of $50 \mathrm{~m} /(300$ days $)$, corresponding to the "strong restoring" option of the Coordinated Ocean Reference Experiments (CORE) described by Griffies et al. (2009). The restoring is seen as a correction to the 
atmospheric water forcing and is thus converted into a water flux. Sea surface salinity restoring seems necessary to allow forced ocean-ice models to equilibrate, because these forced models do not include important feedbacks that exist in the coupled ocean-atmosphere system (for example, the precipitations in a forced ocean model do not depend on the model's evaporation). To avoid a destructive interaction between the SSS restoring and the coastal runoffs, the restoring is suppressed within a distance of $150 \mathrm{~km}$ from the coast. Also, the restoring is limited everywhere in the model to a maximum absolute value of $4 \mathrm{~mm}$ day $^{-1}$. In most DRAKKAR global simulations, the formation of Antarctic bottom water (AABW) is not represented correctly and this induces a spurious downward trend in the Antarctic Circumpolar current transport (Treguier et al., 2010). To avoid this trend, a relaxation of temperature and salinity to climatology is introduced in the dense layers corresponding to AABW. This procedure is described in detail in the appendix of Dufour et al. (2012).

Because the evaporation is recalculated at each time step by the CORE bulk formula using the model's prognostic sea surface temperature, the water balance cannot be achieved a priori. Some modellers apply an "ad hoc" global correction to the model water balance, annually or at each time step (see Griffies et al. (2009), for example). We have chosen not to do so in our simulation, so that the global mean sea level is allowed to drift. During the first half of the simulation, the sea level increases steadily by $45 \mathrm{~cm}$, and then increases less rapidly (about $10 \mathrm{~cm}$ ) during the second half. The increase is $2.5 \mathrm{~cm}$ over the final 10 years of the simulation which are analysed here. This corresponds to a net water flux of $0.03 \mathrm{~Sv}$ integrated over the ocean surface.

\section{Decomposition of the salt transport}

Our global analysis builds on the study of salt transport in the North Atlantic by Treguier et al. (2012), where the meridional transport was decomposed into a time-mean and an eddy transport, which compensated each other to a large extent. This compensation arises if the salinity distribution is stationary in time: in that case, the transport of salt must be zero because evaporation, precipitations and runoffs do not carry any salt. Therefore, the lhs of Eq. (1) is zero and the eddy/mean decomposition of salt transport does not shed light on the relation between the transport and the atmospheric forcing, contrary to the case of the heat transport (Treguier et al., 2012). Here we use a decomposition similar to Bryden and Imawaki (2001) because it clarifies its link with the freshwater flux at the surface of the ocean.

To motivate our method, let us consider first an idealized two-box model (Fig. 2). We define a subpolar box, where precipitation dominates evaporation (a negative $E-P$ is applied), and a subtropical box, where evaporation dominates (positive $E-P$ ). The net water forcing over the domain is zero, so that total volume is conserved. The box ocean is
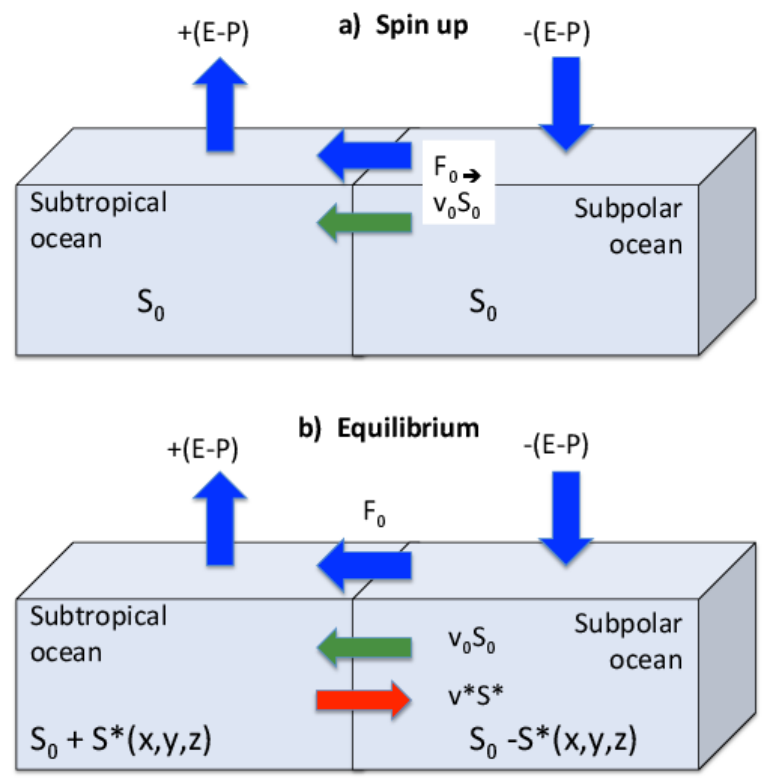

Fig. 2. Box model used to introduce the salt transport decomposition. (a) schematic of the exchanges between the two boxes a short time into the spin-up (typically days or weeks). A barotropic flux $F_{0}$ is set up to carry the excess mass input into the subpolar box by precipitations, in order to avoid indefinite growth of the difference in sea level between the two boxes. It induces a barotropic transport of salt (noted as $v_{0} S_{0}$, green arrow); (b) schematic of the exchanges between the boxes at equilibrium. Salinity anomalies $S^{*}$ develop as a consequence of the barotropic salt flux. Three-dimensional recirculations are established over long timescales (years, decades) which carry salinity anomalies (the transport is noted $v^{*} S^{*}$, red arrow). At equilibrium the salt content of each box is constant and the salt flux $v^{*} S^{*}$ due to the recirculation cancels the salt flux $v_{0} S_{0}$ carried by the barotropic volume flux $F_{0}$.

initially at rest, with uniform density and salinity $S_{0}$. Let us note $F_{0}=-(E-P)$ the water flux, integrated over the area of the subpolar box, in units of volume flux (Sverdrup, $\left.1 \mathrm{~Sv}=10^{6} \mathrm{~m}^{3} \mathrm{~s}^{-1}\right)$. When the forcing is applied it creates an excess volume and elevates the sea surface in the subpolar region relative to the subtropical region. A net flux of water $F_{0}=-(E-P)$ (schematized by a blue arrow in Fig. 2a) is established between the two boxes, to compensate the excess water input into the subpolar box. This transport, driven by pressure forces, is depth independent. In the real ocean, the spin-up of this net mass transport is mediated by fast surface gravity waves that can propagate across the globe with a typical timescale of a day (like tidal waves). In response to a complex pattern of surface water forcing, a geostrophic adjustment takes place and a barotropic circulation is established, the Goldsbrough-Stommel circulation (Huang and Schmitt, 1993), which is one order of magnitude smaller than the wind-forced circulation. For the purpose of 
our demonstration here, we are concerned only by the net transport $F_{0}$ between the two boxes and we assume that this transport is established instantly. Thus, at early times, the velocity $v_{0}$ averaged across the central section transports water of salinity $S_{0}$. It brings not only water, but also salt, into the subtropical box. Evaporation does not carry any salt, so there is no sink of salt in the subtropical box: the salt transport into the subtropical box (noted $v_{0} S_{0}$ in Fig. 2) causes an increase of the salinity there. In the subpolar box, on the contrary, salinity decreases. At later times (Fig. 2b) salinity anomalies $S^{*}=S-S_{0}$ develop in the two boxes. For the model to reach an equilibrium salinity distribution, a recirculation correlated with the salinity anomalies must be established to cancel the transport of salt across the central section: the velocity associated with this recirculation is noted $v^{*}$. This circulation is represented by the red arrow in Fig. 2b. At equilibrium, if the diffusive transport can be neglected, the advective salt transport is zero:

$$
\iint v S=\iint\left(v_{0}+v^{*}(x, y, z)\right) S(x, y, z)=0,
$$

where $v_{0}$ is the velocity averaged across the section and $v^{*}$ the perturbation velocity. The branches of the recirculation $v^{*}$ compensate in mass but because different branches carry water with different salinity, there is a net export of salt from the subtropical to the subpolar boxes, compensating $v_{0} S_{0}$ exactly in the steady state. In the real ocean, this recirculation is set up on periods ranging from months to centuries, through mechanisms such as baroclinic wave propagation, advection by the global ocean circulation, and eddies.

In the world ocean, the large-scale salinity anomalies between basins depicted in Fig. 1 are consistent with the present-day global circulation, both being (at first order) an equilibrium response to the atmospheric forcing. Studies such as Talley (2008) aim at diagnosing the masscompensated recirculation $v^{*}$ which is responsible for maintaining the observed salinity field against the net salt transport forced by the atmospheric water flux. Indeed, the presentation in terms of a "north" and a "south" box in Talley's Eq. (1) is similar to ours, excepted for the fact that Talley's discussion is cast in terms of "freshwater anomalies" rather than salt. Freshwater anomaly, hereafter noted $S_{\mathrm{a}}$, is defined as a negative salinity anomaly normalized by a reference $S_{\mathrm{r}}$ :

$S_{\mathrm{a}}=\left(1-\frac{S}{S_{\mathrm{r}}}\right)$.

In our box model, at equilibrium, the volume transport across the section is equal to the atmospheric water flux north of the section:

$\iint v=F_{0}=-(E-P)$.

Combining Eq. (4) with the condition of vanishing salt flux at equilibrium Eq. (2), one obtains an equation for the transport of freshwater anomaly $S_{\mathrm{a}}$ : $\iint v S_{\mathrm{a}}=\iint v\left(1-\frac{S}{S_{\mathrm{r}}}\right)=-(E-P)$.

This is true for any choice of the reference salinity $S_{\mathrm{r}}$.

The oceanographic literature is quite confusing regarding "freshwater" budgets and "freshwater" transports. From the point of view of basic physics and chemistry, "freshwater" is simply "pure water" (Wijffels et al., 1992; Wijffels, 2001). The mass of pure water is defined unambiguously as the mass of ocean water minus the mass of salt, expressed in units of $\mathrm{kg} \mathrm{m}^{-3}$; the mass of salt represents a small perturbation of about $3 \%$ (the mass of salt contained in $1000 \mathrm{~kg}$ of ocean water $\left(1 \mathrm{~m}^{3}\right)$ is about $\left.35 \mathrm{~kg}\right)$. Thus the ocean mass balance in response to exchanges of water with the atmosphere depends very weakly on the ocean salinity. Indeed, the Boussinesq approximation where the mass balance is replaced by a volume balance, and thus variations of density (and therefore salinity) are neglected in the mass conservation equation, has proven very robust. The Boussinesq approximation is used in many conceptual and numerical models of the ocean circulation (including ORCA12). The key to understanding the salinity distribution of the ocean is not the distinction between transports of pure water or salty water, but rather the distinction of the different salinities carried by the branches of the recirculation $v^{*}$.

The choice of a reference salinity in Eq. (3) is not obvious for modellers. When computing a transport from in situ observations across a hydrographic section, $S_{\mathrm{r}}$ is usually defined as the salinity averaged over the section area. When multiple sections are considered, definitions of $S_{\mathrm{r}}$ appear quite arbitrary in the literature, which hampers the comparison of estimates published by different authors. For example, in her global analysis Talley (2008) chose a constant reference salinity $S_{\mathrm{r}}=34.9$, while Ganachaud and Wunsch (2003) considered the mean salinity of each section; Meijers et al. (2007) chose $S_{\mathrm{r}}=35$ for their model of the Southern Ocean, and Lique et al. (2009) used $S_{\mathrm{r}}=34.8$ for the Arctic. Recently, in a study of the freshwater budget of the Arctic Ocean, Tsubouchi et al. (2012) explained why the salinity averaged along the boundary section of their domain of interest had to be used for $S_{\mathrm{r}}$, and they quantified the errors that could result from a different choice. The complexity of the oceanographer's concept of "freshwater" is demonstrated by the fact that Talley (2008) had to use two different notations (MSv and FSv) for the freshwater transport, according to the section or the domain where it was calculated. Moreover, in some of the publications "freshwater" is used as an abbreviation for the "freshwater anomaly" $S_{\mathrm{a}}$, which creates confusion with the Wijffels et al. (1992) definition of "freshwater" as "pure water". In the present paper, by considering the transport of salt, we avoid the arbitrariness of a reference salinity. 
Following the recommendation of Bryden and Imawaki (2001) for the heat transport we decompose the meridional salt transport into three contributions, one of which is directly related to the atmospheric water flux, so that the decomposition provides the same information as an analysis based on a freshwater anomaly. Let us consider the meridional transport across a zonal section in the global ocean. Just like in the box model, the volume transport must balance the atmospheric forcing in the domain situated north or south of the section. We note \langle\rangle the spatial average on the section (along the zonal and vertical directions $x$ and $z$ ). For the meridional velocity $v$,

$\langle v\rangle(y, t)=\frac{1}{A} \iint_{A} v(x, y, z, t) \mathrm{d} x \mathrm{~d} z$

with $A$ the section area. Defining a time mean (noted by an overbar) we decompose the velocity into the net transport velocity $\langle\bar{v}\rangle$, a time-mean recirculation along the section $\bar{v}^{*}$ and transient fluctuations (noted by primes):

$v(x, y, z, t)=\langle\bar{v}\rangle(y)+\bar{v}^{*}(x, y, z)+v^{\prime}(x, y, z, t)$.

We assume that the time and spatial averages commute, and that the time average of transient fluctuations vanishes. Noting $S$ the salinity, the mean meridional advective salt transport $T$ across the section is thus decomposed into three components:

$\underbrace{A\langle\overline{v S}\rangle}_{T}=\underbrace{A\langle\bar{v}\rangle\langle\bar{S}\rangle}_{T_{\mathrm{m}}}+\underbrace{A\left\langle\overline{v^{*} S^{*}}\right\rangle}_{T_{\mathrm{r}}}+\underbrace{A\left\langle\overline{\left\langle v^{\prime} S^{\prime}\right.}\right\rangle}_{T_{\mathrm{e}}}$.

The subscripts for the three components on the rhs (righthand side) stand for "time-zonal mean", "recirculation", and "eddy", respectively. For the first component we prefer "time-zonal mean" rather than "barotropic" as proposed by Bryden and Imawaki (2001), because most of the time in the literature "barotropic" refers to a transport integrated over depth only, not over a section area. Note also that when the zonal mean is taken for the global ocean, inter-basin exchanges such as the flow through the Bering Strait contribute to the "recirculation", which differs from the analysis of Wijffels et al. (1992), where the recirculation is estimated independently in each ocean basin, and the flow through the Bering Strait is considered as a separate component of the global balance. By the conservation of volume, $T_{\mathrm{m}}$ is related to the integral of the net surface water flux, and to the temporal change of the volume, south of the section (considering Antarctica at $y=y_{\mathrm{s}}$ as the southern boundary of the global ocean):

$$
\begin{aligned}
T_{\mathrm{m}}= & A \overline{\langle v\rangle}\langle\bar{S}\rangle(y)=-\langle\bar{S}\rangle(y) \int_{y_{\mathrm{s}}}^{y} \int_{x}(\overline{E-P-R}) \mathrm{d} x \mathrm{~d} y \\
& -\langle\bar{S}\rangle(y) \int_{y_{\mathrm{s}}}^{y} \int_{x}\left(\frac{\partial \eta}{\partial t}\right) \mathrm{d} x \mathrm{~d} y .
\end{aligned}
$$

In the case of equilibrium over long timescales, $\partial \eta / \partial t$ can be neglected as assumed in Eq. (4). This equation links the water flux over a given region and the transport across the boundary of this region, but it is important to note that the salinity carried by the flow is the salinity averaged over the bounding section, which is not related to the volume average of the salinity in the region. In the literature one finds definitions of freshwater anomalies using a volume-averaged salinity as reference: this is not consistent, as discussed thoroughly by Tsubouchi et al. (2012) in their Sect. 4.1 and in their Appendix A.

When the salinity field is in a steady state (such as in the example of the box model), and if the diffusive transport can be neglected, the total meridional advective transport of salt $T$ in Eq. (8) is zero. In the absence of fluctuations, the timezonal mean transport $T_{\mathrm{m}}$ due to atmospheric forcing is compensated for by the transport of the time-mean recirculation $\bar{v}^{*}$ so that $T_{\mathrm{m}}=-T_{\mathrm{r}}$. In the presence of transient fluctuations, both $\left\langle\overline{v^{*} S^{*}}\right\rangle$ and $\left.\overline{\left\langle v^{\prime} S^{\prime}\right.}\right\rangle$ can play a role in bringing the salinity distribution to equilibrium $\left(T_{\mathrm{m}}=-T_{\mathrm{r}}-T_{\mathrm{e}}\right)$. The decomposition into three components $\left(T_{\mathrm{m}}, T_{\mathrm{r}}\right.$ and $\left.T_{\mathrm{e}}\right)$ is more informative than the decomposition into eddy and time-mean transport ( $T_{\mathrm{e}}$ on one hand, $\bar{T}=T_{\mathrm{m}}+T_{\mathrm{r}}$ on the other hand) used by Treguier et al. (2012), because in the latter case, the link between the salt transport and the atmospheric flux is not made explicit. In the next section we examine the relative role of these components of the salt transport in the ORCA12 simulation.

\section{Global salt balance in ORCA12}

Let us first consider the model volume balance. As shown in Fig. 1 the surface water flux forcing varies with latitude, and its convergences and divergences must be compensated for by a meridional volume transport in the ocean. Our model makes the Boussinesq approximation, and thus conserves volume rather than mass, which is why we speak of volume transport rather than mass transport (as noted in the previous section the mass transports of salty water and pure water are the same within $3 \%$ ). Figure 3 shows the volume transport deduced from the model air-sea water flux $E-P-R$. It has a strong similarity to the volume transport estimated by Large and Yeager (2009), which itself is in overall agreement with the early estimate of Wijffels et al. (1992). The meridional water transport at a global scale is thus quite robust, with its slope reflecting the regions dominated by precipitations (increasing northward transport near the Equator and north and south of $40^{\circ}$ ), or by evaporation (decreasing northward transport in the subtropical regions of both hemispheres). The difference between the model forcing and Large and Yeager (2009) is due to the different evaporation field (computed from ECMWF data instead of NCEP, and using the model sea surface temperature) and to the fact that the restoring to climatological sea surface salinity in the model is implemented 


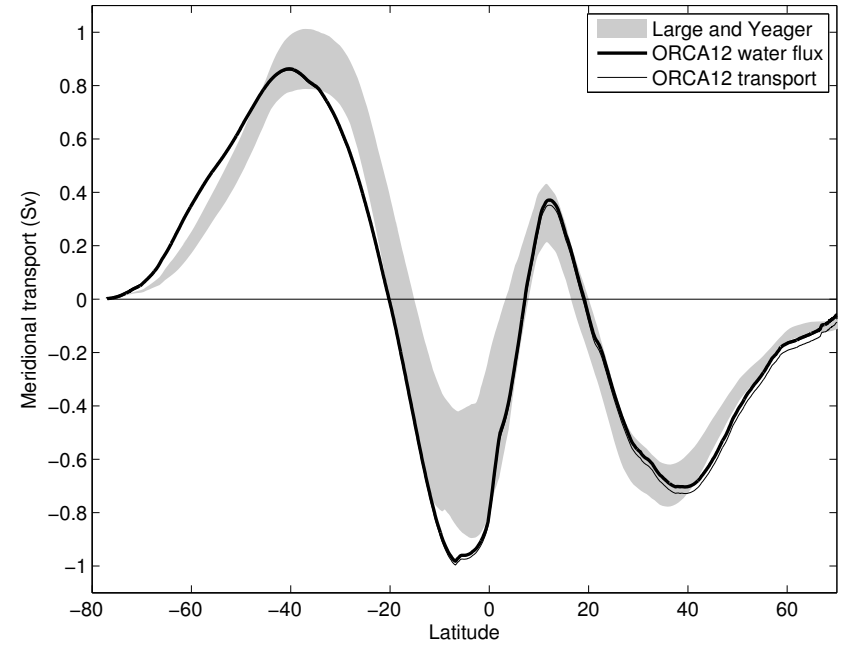

Fig. 3. Meridional transport resulting from the surface water flux in the ORCA12 model (Sv, thick black line), and comparison with Large and Yeager (2009). The grey shading is the envelope of all annual transports resulting from the air-sea fluxes of Large and Yeager (2009) for years 1984 to 2006 (these fluxes are a combination of observations and the NCEP reanalysis). The thin black line is the meridional transport computed directly from the model meridional velocities.

as a correction to the surface water flux (it is thus taken into account in the thick black curve in Fig. 3).

Also plotted in Fig. 3 is the time-zonal mean meridional transport calculated at each latitude from the model velocities. The conservation of volume is exact within machine accuracy in NEMO, so that this transport should match exactly the one implied by the surface fluxes. A small difference appears in Fig. 3: averaged over all latitudes, there is a bias of $0.02 \mathrm{~Sv}$. According to Eq. (9), it is due to the increase in volume of the model ocean over the 10 years of integration (the global exchange of water between the ocean and the atmosphere and land, $E-P-R$, is not exactly zero, as mentioned in Sect. 2). When this effect is taken into account, the freshwater forcing and the model response match exactly. Note that the balance between surface water flux and meridional transport demonstrated by Fig. 3 is independent of the salinity of the model, since it arises from the conservation of volume.

Let us consider the components of the global meridional advective transport of salt defined in Eq. (8). Because ORCA12 is a Boussinesq model we choose units of Sv PSU, a salinity in PSU multiplied by a transport in Sverdrups ( $1 \mathrm{~Sv} \mathrm{PSU} \approx 1 \mathrm{Kton} \mathrm{s}^{-1}$ of salt). Using Eq. (9), the transport by the time-zonal mean velocity averaged at each latitude ( $T_{\mathrm{m}}$, thick black line in Fig. 4) can be compared with a salt transport estimated from data using the $E-P-R$ field of Large and Yeager (2009) for the volume transport, and the salinity $\langle\overline{S(y)}\rangle$ from Levitus (grey shading). As salinity does

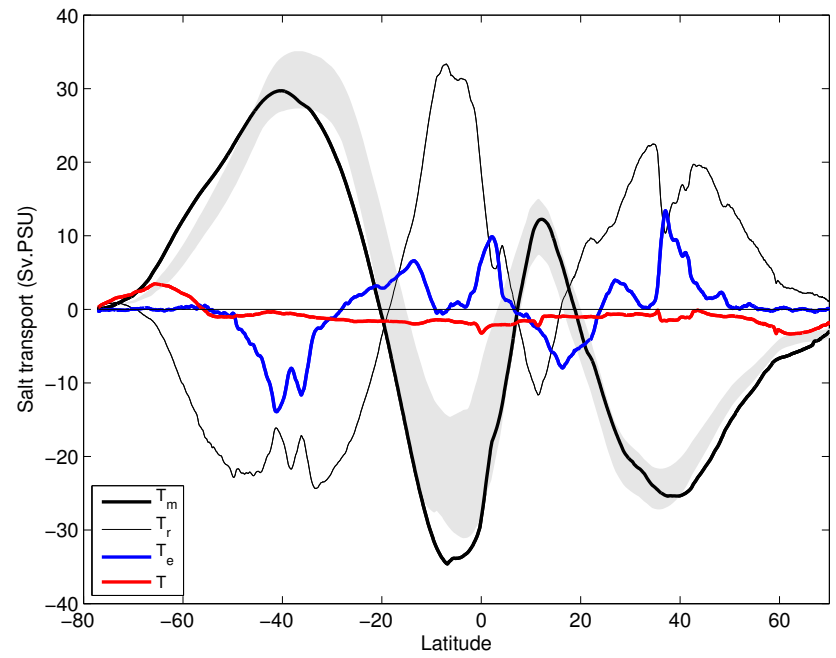

Fig. 4. Decomposition of the global meridional transport of salt in the ORCA12 simulation. See text (Eq. 8) for the explanation of the different terms. The grey shading is the observed salt flux carried by the net volume flux at each latitude: it is computed from the data of Large and Yeager (2009) (similar to Fig. 3) combined with the Levitus depth-averaged salinity field.

not vary much in the global ocean relative to its mean value, both the $T_{\mathrm{m}}$ curve and the grey shading are similar in shape to the volume transports of Fig. 3.

The total transport $T$ (red curve in Fig. 4) is small and almost non-divergent (independent of latitude). This confirms that in ORCA12 the diffusive transport of salt is indeed negligible and thus $T_{\mathrm{m}} \approx-T_{\mathrm{r}}-T_{\mathrm{e}}$. Figure 4 demonstrates that both the mean recirculation (black curve) and the eddy correlations (blue curve) contribute to equilibrate $T_{\mathrm{m}}$ and thus bring the salinity distribution to equilibrium. In the Southern Ocean, our results are similar to Meijers et al. (2007). In their Fig. 12, they have plotted the transport of freshwater $S_{\mathrm{a}}$ which is the opposite of the salt transport. They find that the eddy contribution is large around $40^{\circ} \mathrm{S}$, where it is almost as large as the transport by the mean recirculation, just as in ORCA12. The maximum eddy transport of Meijers et al. in the Southern Ocean $(0.45 \mathrm{~Sv}$ for a reference salinity of $35 \mathrm{PSU})$ corresponds to $15.7 \mathrm{~Sv}$ PSU of salt, slightly larger than ours (14 Sv PSU). One striking difference between our Fig. 4 and Meijers' is the fact that ORCA12 has two distinct minima of eddy salt transport instead of just one located at $40^{\circ} \mathrm{S}$ : this will be explained in the next section. Overall, the southward eddy transport of salt in the Southern Ocean appears very robust, and not strongly dependent on the model resolution, as we find the same value in the $1 / 4^{\circ}$ global simulation ORCA025 analysed by Treguier et al. (2012). This transport seems captured with model resolutions of at least $14 \mathrm{~km}$ at $60^{\circ} \mathrm{S}$ (ORCA025 or Meijers' model), but it was very weak in the $1 / 2^{\circ}$ model of McCann et al. (1994), about 3 Sv PSU only. 

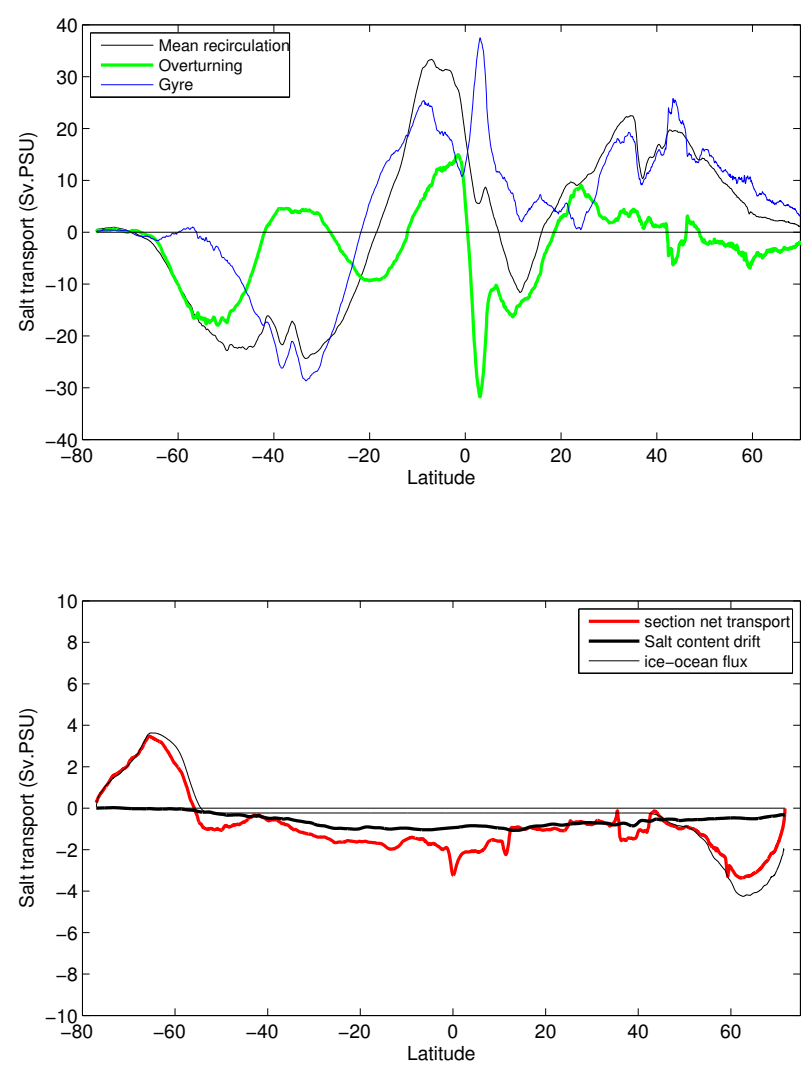

Fig. 5. Further analysis of the meridional transport of salt in the ORCA12 simulation. Top panel: transport by the time-mean recirculation velocity (thin black curve, same as Fig. 4), and its two components: the "overturning" (transport by the zonally averaged, depth-dependent velocity) and the "gyre" component. Bottom panel: contributions from the model drift and the ice-ocean flux which could explain the non-zero total salt transport (the red curve, same as in Fig. 4).

The eddy salt transport $T_{\mathrm{e}}$ is divergent in the subtropical regions of both hemispheres: transient fluctuations transport salt away from the evaporative regions, both equatorward and poleward. In the Northern Hemisphere, between about $15^{\circ} \mathrm{N}$ and $40^{\circ} \mathrm{N}$, the evaporation forces a net convergence of salt of about $37 \mathrm{~Sv}$ PSU (the difference between $T_{\mathrm{m}}$ at these two latitudes) which is compensated for more by the divergence of the eddy flux $T_{\mathrm{e}}$ (up to $20 \mathrm{~Sv}$ PSU) than by the mean circulation.

In many published studies of meridional heat transport, authors have gone one step further in the decomposition by computing separately the transport by the zonally averaged flow dependent on depth, termed "baroclinic transport" by Bryden and Imawaki (2001). This amounts to breaking up the recirculation $v^{*}(x, y, z, t)$ into vertical (overturning) cells and horizontal (gyre) cells. We have performed this decomposition in ORCA12 for both the time-mean and eddy velocities. Regarding the eddy salt transport, it is almost entirely due to the gyres, the eddy overturning component being negligible (not shown). On the other hand, regarding the time-mean recirculation, both overturning and gyre contribute to the meridional transport of salt, as was found to be the case in the Southern Ocean by Meijers et al. (2007) for freshwater transport and by Volkov et al. (2010) for heat transport. The decomposition is shown in Fig. 5 (top panel). South of $50^{\circ} \mathrm{S}$, the salt transport by the mean flow is almost entirely due to the overturning component (in agreement with the Meijers et al., 2007 results; their Fig. 12d). This contrasts with the heat transport which is mainly due to the gyre component at these southern latitudes (Meijers et al., 2007; Volkov et al., 2010).

Although the total advective salt transport $T$ (red curve in Fig. 4) is small, it is not zero and this requires an explanation. We have not been able to calculate all terms of the salinity balance in ORCA12 because some terms (such as the isopycnal Laplacian diffusion) have not been stored and cannot be computed accurately from the 5-day averages. $T$ is shown again in Fig. 5b. It is significant north and south of $60^{\circ}$, where a divergence of salt transport is induced by the ice-ocean flux, represented in the model by a virtual salt flux. Where ice forms, there is a flux of salt into the ocean due to brine rejection; salt is removed equatorward where ice melts. An estimate of the model ice-ocean flux is plotted for comparison: the good correspondence with $T$ in shape and in magnitude shows that ice-ocean fluxes are the main cause of salt transport divergence poleward of $60^{\circ}$. South of $60^{\circ} \mathrm{S}$, the relaxation of temperature and salinity in the Antarctic bottom water $(\mathrm{AABW})$ also contributes to the non-zero salt transport. At mid-latitudes, the slight decrease in $T$ in the Southern Hemisphere and increase in the Northern Hemisphere are in agreement with the change in salt content (thick black line). The difference between the red and the black curves in ice-free areas is probably due to the salt transport by the parameterized lateral diffusion.

\section{Temporal and spatial scales of eddy salt transport}

To go further in the spatial analysis of eddy salt fluxes, we have calculated $T_{\mathrm{e}}$ for the different ocean basins (Fig. 6). Moreover, as a first step in analysing the timescales, we have attempted to separate the contribution of the seasonal cycle to the velocity-salinity correlations. A method was proposed in Treguier et al. (2012) to calculate it. First, an averaged seasonal cycle is estimated from a long simulation. Here we use 70 years or ORCA12, from year 16 to year 85 : it is possible because the calculation can be performed from monthly averages, which are available for the whole duration of the experiment (unlike the 5-day averages used for the estimation of $T_{\mathrm{e}}$, which are available only for the last ten years). The 12monthly values of velocity and salinity averaged from year 16 to $85, \tilde{v}$ and $\tilde{S}$, are used to compute a salt transport $\bar{v} \tilde{S}$. The difference with the transport by the mean flow $\bar{v} \bar{S}$ is the contribution of the seasonal cycle $T_{\mathrm{s}}$, represented by a thin line 

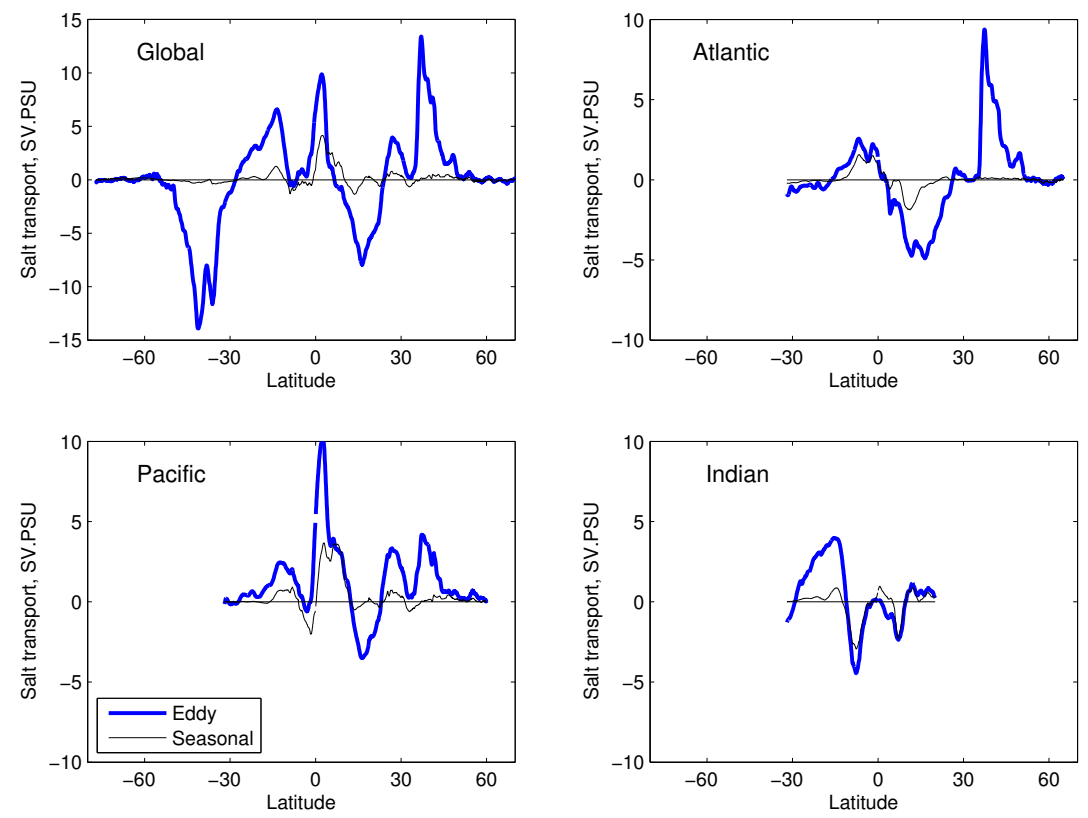

Fig. 6. Eddy and seasonal contributions to the meridional transport of salt in the ORCA12 simulation.

in Fig. 6, allowing comparison with $T_{\mathrm{e}}$. At the global scale, the seasonal contribution is relatively small outside the tropics, suggesting that velocity-salinity correlations arise from non-linear eddy variability there. On the other hand, $T_{\mathrm{s}}$ is non-negligible in the tropics, especially for the peak near $2^{\circ} \mathrm{N}$, which is explained for half its amplitude by the seasonal cycle. This contrast between the tropics and subtropics is confirmed by a map of the divergence of $T_{\mathrm{S}}$ (Fig. 7, bottom panel).

In the tropics the seasonal contribution $T_{\mathrm{S}}$ in ORCA12 is much larger than the estimate made by Wijffels (2001) using the correlation between sea surface salinity and Ekman velocities. Comparing the seasonal transport in the different basins (Fig. 6) with Wijffels, we note that in the Indian Ocean there are two minima of $T_{\mathrm{s}}$ north and south of the Equator, and in the Pacific Ocean there is a maximum north of the Equator, just as in Wijffels (2001)'s Fig. 6.2.4, but the amplitude is twice as large in our case. In the Atlantic Wijffels's estimate and ours have opposite signs. These differences are probably due to the fact that $T_{\mathrm{s}}$ in the model includes all the seasonal variations of salinity and currents, and not the Ekman component only.

Let us come back to the total eddy contribution $T_{\mathrm{e}}$ integrated in each ocean basin (Fig. 6). In the Atlantic Ocean it is similar to Treguier et al. (2012), who used a regional model at the same resolution (NATL12). The eddy salt transport is positive (to the north) near the Equator, negative in the southern part of the subtropical gyre, peaking at a latitude of $15^{\circ} \mathrm{N}$, and positive again in the northern part of the subtropical gyre, peaking near $36^{\circ} \mathrm{N}$. One notable difference between ORCA12 and NATL12 is the amplitude of this latter peak, which is lower by $25 \%$ in ORCA12. This is not surprising because this peak is mainly due to fluctuations at the western boundary related to the dynamics of the Gulf Stream separation, which is model dependent (Treguier et al., 2012). The peak in the tropics near $2^{\circ} \mathrm{N}$ is also lower in ORCA12 compared with NATL12 and the seasonal $T_{\mathrm{s}}$ is larger in comparison with the total $T_{\mathrm{e}}$. This is probably due to the fact that NATL12 is forced by interannual atmospheric data, causing large year-to-year variations that also contribute to $T_{\mathrm{e}}$ (Treguier et al. (2012), see their Fig. 6), while our ORCA12 simulation is forced by a repeated seasonal cycle: only seasonal and turbulent variability are present. In the Pacific Ocean, the maximum value of $T_{\mathrm{e}}$ is found north of the Equator at $2.2^{\circ} \mathrm{N}$, where tropical instability waves are active. These waves transport heat meridionally (e.g. Menkes et al., 2006), so one may assume that they also contribute to the transport of salt. Comparing the two left panels of Fig. 6 shows that the global maximum of $T_{\mathrm{e}}$ found at that latitude is almost completely accounted for by the Pacific Ocean. In the Indian Ocean, there is a large contrast between the tropical and northern Indian oceans, where the transient salt transport is almost entirely seasonal, and the region south of $10^{\circ} \mathrm{S}$, where transients are due to eddies.

A global map of the divergence of $T_{\mathrm{e}}$ is plotted in Fig. 7. This field is dominated by small scales, especially at high latitudes, and is similar to Fig. 11 of Meijers et al. (2007) for the Southern Ocean. The divergence of $T_{\mathrm{e}}$ is large in the Antarctic Circumpolar current and in boundary currents. The importance of the hotspots of eddy activity such as the Agulhas retroflexion or the Brazil-Malvinas confluence zone does not stand out in Fig. 7 because the colour scale is saturated, but in 
fact these eddy-rich regions are responsible for the two distinct minima of $T_{\mathrm{e}}$ at $41^{\circ} \mathrm{S}$ and $36^{\circ} \mathrm{S}$ found in Fig. 4. By considering the zonally cumulated transport values (not shown), we have found that the meridional eddy salt transport at $41^{\circ} \mathrm{S}$ is due to the Agulhas retroflexion (south of Africa and in the Indian sector of the Southern Ocean) and the one at $36^{\circ} \mathrm{S}$ is due to the Brazil-Malvinas confluence as well as the eddies around Australia. These two minima did not appear in the Meijers et al. (2007) model because in their model the Brazil-Malvinas confluence zone was located too far south, and contributed to the meridional salt transport in the same latitude band as the Agulhas retroflexion. In the tropics, the patterns of divergence are qualitatively different (Fig. 7) and organized into zonal bands, which is due to seasonal variability as shown by the comparison of the two panels in Fig. 7 . The positive divergence of salt which contributes to flushing salt out of the subtropical gyres toward the Equator is distributed over the whole basin width, as appears from the large red areas in the Atlantic and Pacific around $15^{\circ}$, and in the southern Indian Ocean around $20^{\circ} \mathrm{S}$. These regions are characterized by westward propagating eddies and waves. In the Indian Ocean, the maximum in meridional eddy transport of salt near $20^{\circ} \mathrm{S}$ is clearly related to the westward propagating eddies generated by the Leeuwin Current along the west coast of Australia. The contribution of the Indian Ocean to the global transport of salt is the dominant one at this latitude, with eddies in the South Atlantic and South Pacific playing a lesser role (Fig. 6). In contrast to the tropics, at the poleward limit of the subtropical gyres, the fluctuations at the western boundaries dominate $T_{\mathrm{e}}$. This is true in the Atlantic (Gulf Stream) and the Pacific (Kuroshio). This qualitative difference in mechanisms for salt transport between the northern and southern boundaries of the subtropical gyres was noted by Treguier et al. (2012) for the case of the North Atlantic basin (see their Figs. 7 and 9).

Regarding the Pacific Ocean, Stammer (1998) had suggested that the eddy salt flux was northward over the whole North Pacific. His estimate relied on the hypothesis of a diffusion coefficient constant in depth and acting on the climatological salinity gradients in the top $1000 \mathrm{~m}$ of the ocean. In contrast, ORCA12 has a southward eddy flux at $15^{\circ} \mathrm{N}$ (Fig. 6). An examination of the meridional gradients of salinity in the Pacific Ocean shows that although the salinity averaged over the top $1000 \mathrm{~m}$ decreases from the Equator to the Bering Strait (which explains Stammer's results), the salinity averaged over the top $200 \mathrm{~m}$ shows a subtropical maximum (Fig. 1). Stammer's estimate would have been in closer agreement with our model if based on the gradients of salinity over the top $200 \mathrm{~m}$ of the ocean rather than $1000 \mathrm{~m}$, a feature already noted by Treguier et al. (2012) in the case of the Atlantic Ocean. Overall, the model agrees with a diffusive behaviour of the eddies, which act to transfer salt laterally along isopycnals away from the salinity maxima located in the centre of the subtropical gyres.

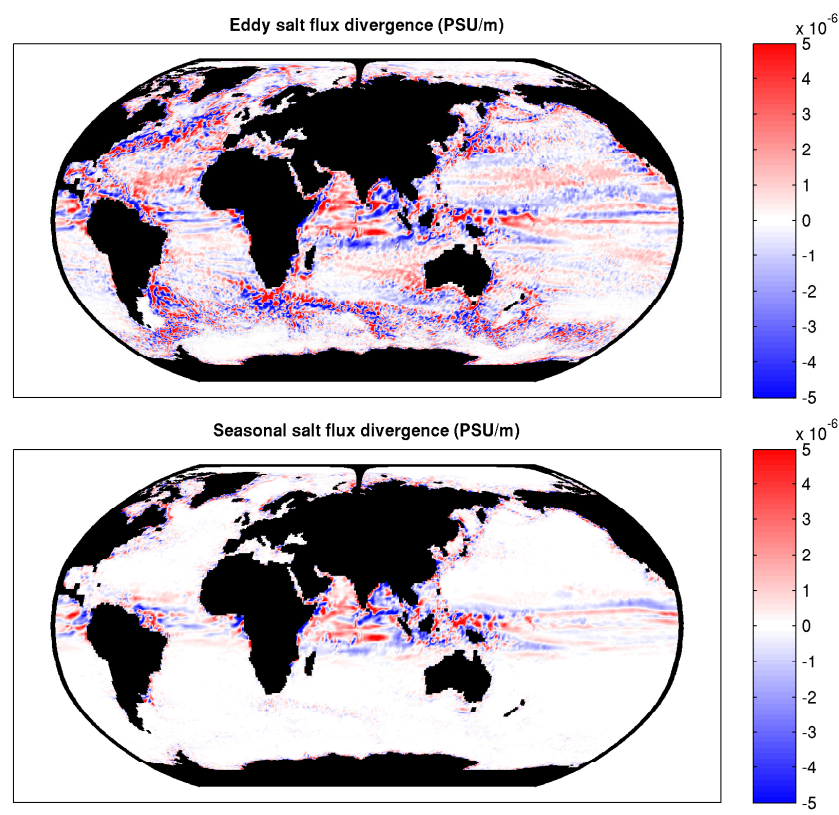

Fig. 7. Divergence of the eddy salt transport in the ORCA12 simulation, computed for $12 \times 12$ grid point boxes to enhance readability. It is integrated vertically and thus expressed in units of PSU ms s ${ }^{-1}$. The colour scale is saturated in the red and blue at $5 \times 10^{-6} \mathrm{PSU} \mathrm{m} \mathrm{s}^{-1}$ (the maxima and minima of the field are about 40 times larger). Top panel: total eddy component; bottom panel: seasonal contribution only.

It is interesting to compare our results with the study of Talley (2008), who published global estimates of the transport of freshwater anomalies $S_{\mathrm{a}}$, summarized in tables and in her Fig. 5. In the Atlantic Basin between $35^{\circ} \mathrm{S}$ and $45^{\circ} \mathrm{N}$, Talley found that the divergence of salt driven by the timemean circulation $v^{*}$ was $0.59 \mathrm{~Sv}$ (in units of "freshwater", using a reference salinity of 34.9). This was in agreement with her estimate of the atmospheric forcing in the same region $(0.57 \mathrm{~Sv})$ based on NCEP. In our model the evaporation in the Atlantic Basin is stronger $(E-P-R=0.69 \mathrm{~Sv})$ and it is balanced not only by the time-mean circulation, but also by the divergence of the eddy flux $T_{\mathrm{e}}$ : converted into freshwater anomaly with $S_{\mathrm{r}}=34.9$, the eddy divergence is $0.12 \mathrm{~Sv}$, a value which cannot be neglected when computing the salt balance for the global ocean. The contribution of the eddy divergence for the Pacific Basin is non-negligible, 0.05 Sv, as large as Talley's estimate of the divergence by the mean recirculation $(0.06 \mathrm{~Sv})$. Talley's estimate from hydrology was certainly too low, because it did not compensate for the NCEP forcing over Talley's Pacific region (which was $0.16 \mathrm{~Sv}$ in her Table 4). The forcing of our model is even higher $(0.36 \mathrm{~Sv}$ over the same region) and the divergence of the transport by the time-mean recirculation is also larger, more important in fact than the eddy divergence. 


\section{Conclusions}

In this paper we have presented the salt balance of a $1 / 12^{\circ}$ resolution global ocean simulation. To our knowledge the salt budget had never been analysed globally in an eddying ocean model (McCann et al., 1994's model did not include the Arctic Ocean, and its resolution was only $1 / 2^{\circ}$ ). We have decomposed the meridional salt transport into three components:

$T=T_{\mathrm{m}}+T_{\mathrm{r}}+T_{\mathrm{e}}$.

The first component is $T_{\mathrm{m}}$, the salt transport by the net meridional velocity (the time-mean velocity averaged zonally and over depth at each latitude). This velocity is directly forced by the atmospheric water flux at the surface of the ocean and by coastal runoffs $(E-P-R)$, so that $T_{\mathrm{m}}$ can be compared with estimates of $E-P-R$ from observations combined with a climatology of in situ salinity (as shown in our Fig. 4). Its maxima and minima are around $30-35$ Sv PSU in the Southern Hemisphere and 15-20 Sv PSU in the Northern Hemisphere. The convergence of this time-zonal mean transport brings extra salt into the evaporation-dominated subtropics and removes salt from the precipitation-dominated regions, near the intertropical convergence zone and in the polar regions.

Our model demonstrates how the time-mean ocean recirculations and the correlation between salinity and velocity eddy fluctuations $\left(T_{\mathrm{r}}\right.$ and $\left.T_{\mathrm{e}}\right)$ jointly contribute to counteract this time-zonal mean transport $T_{\mathrm{m}}$ and bring the total meridional transport of salt close to zero, a necessary condition for the model salinity distribution to reach an equilibrium. We note however that north and south of $60^{\circ}$, there is a net transport of salt in the ocean, compensating for the mechanism of sea ice formation at high latitudes and transport of sea ice to lower latitudes where it melts. Between $15^{\circ} \mathrm{S}$ and $15^{\circ} \mathrm{N}$, the intertropical convergence zone imports salt mainly through the time-mean recirculations. The eddy transport $T_{\mathrm{e}}$ plays a lesser role and is caused by seasonal variations rather than random eddies. Equatorward of the subtropical gyres $\left(20^{\circ} \mathrm{S}\right.$ and $\left.20^{\circ} \mathrm{N}\right), T_{\mathrm{e}}$ is comparable to $T_{\mathrm{r}}$ (5 to $10 \mathrm{SvPSU}$ ), and it is due to westward propagating eddies and waves distributed across the whole ocean basins. Near the subtropical fronts at $40^{\circ} \mathrm{S}$ and $40^{\circ} \mathrm{N}$, salt is exported from the subtropics, half by the eddy transport $T_{\mathrm{e}}$ and half by the mean recirculations. At these latitudes the significant contributions to $T_{\mathrm{e}}$ are localized in space in intense boundary currents such as the Gulf Stream, the Kuroshio, the Brazil-Malvinas confluence zone and the Agulhas retroflexion. In the centre of the subtropical gyres, the eddy salt transport is negligible. The same is true in the subpolar regions in our model, but there it is unclear whether this is robust or rather due to as yet insufficient resolution in these regions, where the Rossby radius of deformation becomes smaller than the grid size.

Overall, our analysis has confirmed that eddies are important for the meridional transport of salt. An interesting perspective will be to quantify their role in the interannual to decadal variability of the salinity. There are ORCA12 simulations with interannually varying atmospheric forcing that are available for this purpose (Deshayes et al., 2013). Multiple numerical simulations are useful in order to assess the robustness of the eddy transport estimates: we have computed the time-mean meridional salt transports in DRAKKAR simulations at $1 / 4^{\circ}$ and $1 / 12^{\circ}$ resolution, and we have found that at first order the three components $T_{\mathrm{m}}, T_{\mathrm{r}}$ and $T_{\mathrm{e}}$ of the salt transport have very similar amplitude and latitudinal dependence. This is confirmed by the good agreement between the ORCA12 simulation presented here and the Southern Ocean model of Meijers et al. (2007).

We hope that the present study can convince numerical modellers that the mass (or volume) balance should be analysed separately from the salt balance. The combination of the two equations into a budget for a "freshwater anomaly" is not really useful, especially at the global scale. The expression "freshwater transport" brings to mind a picture of rain falling onto the ocean and being carried around the global ocean while remaining "fresh", which is misleading. When mass is added somewhere in the ocean, by rain or river runoff, the ocean mass is rearranged rapidly through surface gravity waves and barotropic adjustment. This rapid adjustment carries seawater around, not pure water. Ocean water masses are either relatively fresh (as in the Arctic) or salty (in the subtropical gyres); while it may seem intuitive to define "fresh" anomalies (the opposite of salinity anomalies) when studying the salinity balance of the Arctic, it is not so when considering the pathways of the maximum salinity waters (e.g. Blanke et al., 2002). In an analysis of the global ocean, there is no reason to use in a systematic fashion the negative of the observed quantity (salinity). Salinity can be considered as a tracer which obeys a conservation equation (e.g. Griffies, 2004) and thus the salt budget alone is sufficient to understand how the global ocean maintains its observed quasi-steady salinity distribution in the presence of atmospheric water fluxes. The decomposition of the salt transport, as demonstrated here, allows us to link the atmospheric forcing and the transport of salt by the different components of the ocean circulation without the need to define anomalies relative to an arbitrary reference salinity. In fact, the same method could be used when computing balances from observations, because inevitably a hypothesis has to be made about the net transport, and this hypothesis provides $T_{\mathrm{m}}$ indirectly when it cannot be computed directly. As a result, the concept of "freshwater anomaly" seems altogether unnecessary for the understanding of the global salinity distribution in the ocean.

Acknowledgements. The ORCA12 numerical simulation has been run at the GENCI computing centre in Orsay (IDRIS), with the help of Pascal Voury and Philippe Collinet. Albanne Lecointre helped set up the ORCA12 configuration. The authors acknowledge support from CNRS (except R. Bourdalle-Badie, who is supported by MERCATOR-Ocean, and Camille Lique by NERC). 
The DRAKKAR project is funded by LEFE-INSU, Ifremer and Mercator-Ocean. A. M. Treguier thanks Lynne Talley, Gokhan Danabasoglu and Steve Griffies for useful discussions during the meeting of the Working Group on Ocean Model Development in Hobart.

Edited by: M. Hecht

\section{References}

Barnier, B., Madec, G., Penduff, T., Molines, J. M., Treguier, A. M., Le Sommer, J., Beckmann, A., Biastoch, A., Boning, C., Dengg, J., Derval, C., Durand, E., Gulev, S., Remy, E., Talandier, C., Theetten, S., Maltrud, M., McClean, J., and De Cuevas, B.: Impact of partial steps and momentum advection schemes in a global ocean circulation model at eddy-permitting resolution, Ocean Dynam., 56, 543-567, 2006.

Blanke, B., Arhan, M., Lazar, A., and Prévost, G.: A Lagrangian numerical investigation of the origins and fates of the salinity maximum water in the Atlantic, J. Geophys. Res.-Oceans, 107, 27-1-27-15, 2002.

Brodeau, L., Barnier, B., Treguier, A., Penduff, T., and Gulev, S.: An ERA40-based atmospheric forcing for global ocean circulation models, Ocean Model., 31, 88-104, 2010.

Bryden, H. and Imawaki, S.: Ocean heat transport, in: Ocean Transport of Fresh Water, Ocean Circulation and Climate, edited by: Siedler, G., Church, J., and Gould, J., 455-474, Academic Press, London, 2001.

Dai, A. and Trenberth, K.: Estimates of freshwater discharge from continents: latitudinal and seasonal variations, J. Hydrometeorol., 3, 660-687, 2002.

Deshayes, J., Treguier, A., Barnier, B., Lecointre, A., Sommer, J. L., Molines, J.-M., Penduff, T., Bourdalle-Badie, R., Drillet, Y., Garric, G., Benshila, R., Madec, G., Biastoch, A., Boning, C., Scheinert, M., Coward, A. C., and Hirschi, J.: Oceanic hindcast simulations at high resolution suggest that the Atlantic MOC is bistable, Geophys. Res. Lett., 40, 3069-3073, 2013.

Drakkar Group, T.: Eddy permitting ocean circulation hindcasts of past decades, Clivar Exchanges, 42, 8-10, 2007.

Dufour, C. O., Sommer, J. L., Zika, J. D., Gehlen, M., Orr, J. C., Mathiot, P., and Barnier, B.: Standing and transient eddies in the response of the Southern Ocean meridional overturning to the southern annular mode, J. Climate, 25, 6958-6974, 2012.

Durack, P. J., Wijffels, S. E., and Matear, R. J.: Ocean salinities reveal strong global water cycle intensification during 1950-2000, Science, 336, 455-458, 2012.

Ganachaud, A. and Wunsch, W.: Large scale ocean heat and freshwater transports during the world ocean circulation experiment, J. Climate, 16, 696-705, 2003.

Griffies, S. M.: Fundamentals of Ocean Climate Models, Princeton University Press, Princeton, USA, 2004.

Griffies, S. M., Biastoch, A., Boening, C., Bryan, F., Danabasoglu, G., Chassignet, E. P., England, M. H., Gerdes, R., Haak, H., Hallberg, R. W., Hazeleger, W., Jungclaus, J., Large, W. G., Madec, G., Pirani, A., Samuels, B. L., Scheinert, M., Sen Gupta, A., Severijns, C. A., Simmons, H. L., Treguier, A. M., Winton, M., Yeager, S., and Yin, J.: Coordinated Ocean-ice Reference Experiments (COREs), Ocean Model., 26, 1-46, 2009.
Huang, R. and Schmitt, R. W.: The Goldsbrough-Stommel circulation of the world oceans, J. Phys. Oceanogr., 23, 1277-1284, 1993.

Hurlburt, H. E., Brassington, G. B., Drillet, Y., Kamachi, M., Benkiran, M., Bourdalle-Badie, R., Chassignet, E. P., Jacobs, G. A., Le Galloudec, O., Lellouche, J. M., Metzger, E. J., Smedstad, O. M., and Wallcraft, A. J.: High-resolution global and basin-scale ocean analyses and forecasts, Oceanography, 22, 110-127, 2009.

Large, W. and Yeager, S.: Diurnal to decadal global forcing for ocean sea ice models: the data set and fluxes climatologies, Rep. NCAR/TN-460+STR, National Center for Atmospheric Research, Boulder, Colorado, 2004.

Large, W. G. and Yeager, S. G.: The global climatology of an interannually varying air-sea flux data set, Clim. Dynam., 33, 341364, 2009.

Lique, C., Treguier, A., Scheinert, M., and Penduff, T.: A modelbased study of ice and freshwater transport variabilities along both sides of Greenland, Clim. Dynam., 33, 685-705, 2009.

Madec, G.: NEMO ocean engine, Note du Pole de modelisation, Institut Pierre-Simon Laplace (IPSL), France, 27, 1288-1619, 2008.

Maltrud, M. and McClean, J.: An eddy resolving global 1/10 ocean simulation, Ocean Model., 8, 31-54, 2005.

Maze, G., Deshayes, J., Marshall, J., Treguier, A., Chronis, A., and Vollner, L.: Surface vertical PV fluxes and subtropical mode water formation in an eddy-resolving numerical simulation, DeepSea Res. Pt. II, 91, 128-138, 2013.

McCann, M. P., Semtner, A., and Chervin, R.: Transports and budgets of volume, heat and salt from a global eddy-resolving ocean model, Clim. Dynam., 10, 59-80, 1994.

Meijers, A. J., Bindoff, N. L., and Robert, J.: On the total, mean and eddy heat and freshwater transports in the Southern Hemisphere of a $1 / 8^{\circ} \times 1 / 8^{\circ}$ global ocean models, J. Phys. Oceanogr., 37, 277-295, 2007.

Menkes, C., Vialard, J., Kennan, S., Boulanger, J.-P., and Madec, G.: A modeling study of the impact of tropical instability waves on the heat budget of the eastern equatorial Pacific, J. Phys. Oceanogr., 36, 847-865, 2006.

Penduff, T., Juza, M., Brodeau, L., Smith, G. C., Barnier, B., Molines, J.-M., Treguier, A.-M., and Madec, G.: Impact of global ocean model resolution on sea-level variability with emphasis on interannual time scales, Ocean Sci., 6, 269-284, doi:10.5194/os6-269-2010, 2010.

Penduff, T., Juza, M., Barnier, B., Zika, J., Dewar, W., Treguier, A., Molines, J., and Audiffren, N.: Sea-level expression of intrinsic and forced ocean variabilities at interannual time scales, J. Climate, 24, 5652-5670, 2011.

Roullet, G. and Madec, G.: salt conservation, free surface, and varying levels: a new formulation for ocean general circulation models, J. Geophys. Res., 105, 23927-23942, 2000.

Silva, T., Bigg, G., and Nicholls, K.: Contribution of giant icebergs to the Southern Ocean freshwater flux, J. Geophys. Res., 111, C03004, doi:10.1029/2004JC002843, 2006.

Stammer, D.: On eddy characteristics, Eddy transports, and mean flow properties, J. Phys. Oceanogr., 28, 727-739, 1998.

Talley, L. D.: Freshwater transport estimates and the global overturning circulation: Shallow, deep, and throughflow components, Prog. Oceanogr., 78, 257-303, 2008. 
Terray, L., Corre, L., Cravatte, S., Delcroix, T., Reverdin, G., and Ribes, A.: Near-surface salinity as nature rain gauge to detect human influence on the tropical water cycle, J. Climate, 25, 958977, 2012.

Timmermann, R., Goose, H., Madec, G., Fichefet, T., Ethe, C., and Duliere, V.: On the representation of high latitude processes in the ORCA-LIM global coupled sea ice-ocean model, Ocean Model., 8, 175-201, 2005.

Treguier, A., Sommer, J. L., Molines, J., and de Cuevas, B.: Response of the Southern Ocean to the southern annular mode: interannual variability and multidecadal trend, J. Phys. Oceanogr., 40, 1659-1668, 2010.

Treguier, A. M., Deshayes, J., Lique, C., Dussin, R., and Molines, J. M.: Eddy contributions to the meridional transport of salt in the North Atlantic, J. Geophys. Res., 117, C05010, doi:10.1029/2012JC007927, 2012.

Tsubouchi, T., Bacon, S., Garabato, A. C. N., Aksenov, Y., Laxon, S. W., Fahrbach, E., Beszczynska-Möller, A., Hansen, E., Lee, C. M., and Ingvaldsen, R. B.: The Arctic Ocean in summer: a quasi-synoptic inverse estimate of boundary fluxes and water mass transformation, J. Geophys. Res., 117, C01024, doi:10.1029/2011JC007174, 2012.
Volkov, D., Fu, L., and Lee, T.: Mechanisms of meridional heat transport in the Southern Ocean, Ocean Dynam., 60, 791-801, 2010.

Wijffels, S.: Towards a physical understanding of the North Atlantic: a review of model studies, in: Ocean Transport of Fresh Water, Ocean Circulation and Climate, edited by: Siedler, G., Church, J., and Gould, J., 475-488, Academic Press, London, 2001.

Wijffels, S., Bryden, R. W. S. H. L., and Stigebrandt, A.: Transport of freshwater by the oceans, J. Phys. Oceanogr., 22, 155-162, 1992.

Yu, L.: A global relationship between the ocean water cycle and near-surface salinity, J. Geophys. Res., 116, C10025, doi:10.1029/2010JC006937, 2011. 